Article

\title{
Conductivity, Viscosity, Spectroscopic Properties of Organic Sulfonic Acid solutions in Ionic Liquids
}

\author{
Anh T. Tran, Jay Tomlin, Phuoc H. Lam, Brittany L. Stinger, Alexandra D. Miller, \\ Dustin J. Walczyk, Omar Cruz, Timothy D. Vaden * (D) and Lei Yu* \\ Department of Chemistry and Biochemistry, Rowan University, Glassboro, NJ 08028, USA; \\ trana27@students.rowan.edu (A.T.T.); tomlin37@students.rowan.edu (J.T.); lamp90@students.rowan.edu (P.H.L.); \\ stingerb0@students.rowan.edu (B.L.S.); millera7@students.rowan.edu (A.D.M.); \\ walczykd8@students.rowan.edu (D.J.W.); cruzgarcia1500@gmail.com (O.C.) \\ * Correspondence: vadent@rowan.edu (T.D.V.); yu@rowan.edu (L.Y.)
}

Received: 14 June 2019; Accepted: 25 September 2019; Published: 1 October 2019

check for updates

\begin{abstract}
Sulfonic acids in ionic liquids (ILs) are used as catalysts, electrolytes, and solutions for metal extraction. The sulfonic acid ionization states and the solution acid/base properties are critical for these applications. Methane sulfonic acid (MSA) and camphor sulfonic acid (CSA) are dissolved in several IL solutions with and without bis(trifluoromethanesulfonyl)imine (HTFSI). The solutions demonstrated higher conductivities and lower viscosities. Through calorimetry and temperature-dependent conductivity analysis, we found that adding MSA to the IL solution may change both the ion migration activation energy and the number of "free" charge carriers. However, no significant acid ionization or proton transfer was observed in the IL solutions. Raman and IR spectroscopy with computational simulations suggest that the HTFSI forms dimers in the solutions with an N-H-N "bridged" structure, while MSA does not perturb this hydrogen ion solvation structure in the IL solutions. CSA has a lower solubility in the ILs and reduced the IL solution conductivity. However, in IL solutions containing $0.4 \mathrm{M}$ or higher concentration of HTFSI, CSA addition increased the conductivity at low CSA concentrations and reduced it at high concentrations, which may indicate a synergistic effect.
\end{abstract}

Keywords: ionic liquid; sulfonic acid; solution properties

\section{Introduction}

Investigations and reports about ionic liquids (ILs) have been burgeoning in the past two decades due to their unique chemical and physical properties as organic liquid substances. These properties include a combination of negligible vapor pressure, non-flammability, good stability, good solvents for many organic and inorganic compounds, good ionic conductivity, and large electrochemical windows [1]. Because of these advantages, ILs have been broadly used in organic reactions as solvents and catalysts and in electrochemical devices as electrolytes. Many of the typical ILs are "neutral" in terms of their acid/base properties. Acidic ionic liquids (AILs) contain active protons from Brønsted acids present as cations, anions, or solutes in IL solutions. Their acidity provides active hydrogen ions $\left(\mathrm{H}^{+}\right)$for numerous chemical and electrochemical applications [2]. In this context, the activity, ionization, solvation, and transportation of the acidic protons $\left(\mathrm{H}^{+}\right)$in the ILs are critical fundamental knowledge to understand the structure-property relations in the ILs and to optimize their functions in different areas of applications.

In our previous reports, we investigated the properties of a series of acid solutions in ILs such as 3-butyl-1-methylimidazolium tetrafluoroborate $\left(\mathrm{BMIBF}_{4}\right)$ [3], 3-butyl-1-methylimidazolium bis(trifluoromethanesulfonyl)imide (BMITFSI) [4,5], N-butyl-N-methylpyrrolidinium 
bis(trifluoromethanesulfonyl)imide (PyrrTFSI) [6], and 3-ethyl-1-methylimidazolium acetate (EMIOAc) [7]. It has been concluded that the AIL properties strongly depend on the structures of ILs or acids. When a very strong acid, such as $\mathrm{HBF}_{4}$ (in its aqueous solution), is dissolved in an IL, the $\mathrm{H}^{+}$ ions will protonate water molecules in the solution and the non-volatile $\mathrm{H}_{3} \mathrm{O}^{+}$ion will remain in the IL solution when water molecules are evaporated. On the other hand, when a weak acid (e.g., acetic acid) is dissolved in an IL, the acid does not dissociate significantly, and remains a neutral molecule in the solution. Bis(trifluoromethanesulfonyl)imine (HTFSI) is a typical strong acid in aqueous solutions, but a moderate one in non-aqueous solutions. In HTFSI/IL solutions, HTFSI molecules and TFSI ions can form dimers with an N-H-N "bridged" structure. In this paper, we investigate the properties of organic sulfonic acid ( $\left.\mathrm{R}_{-} \mathrm{SO}_{3} \mathrm{H}\right) / \mathrm{IL}$ solution properties with a combination of various methods, including conductivity, viscosity, calorimetry, spectroscopy, and computational studies.

Many organic sulfonic acids, $\mathrm{R}-\mathrm{SO}_{3} \mathrm{H}$, are relatively strong. For example, the ionization constant $\left(\mathrm{pK}_{\mathrm{a}}\right)$ of methane sulfonic acid (MSA) is -1.9 , while toluenesulfonic acid has a $\mathrm{pK}_{\mathrm{a}}$ of $-2.8[8,9]$. Sulfonic acids have applications not only as bulk materials or in their aqueous solutions, but also in IL solutions. As sources of active protons, sulfonic acids are less expensive and more stable compared with HTFSI. Moreover, the properties of the organic sulfonic acids can be adjusted by changing the structure of the R-group.

Sulfonic acids in ILs have various applications. First, sulfonic acid-based AILs have been used as solvents and catalysts for Fischer esterification reactions and for alcohol, amine, and starch acetylation reactions [10-26]. When AILs are used in these reactions, they are "bi-functional", as solvents and homogeneous catalysts. In many of the catalytic reactions, the active proton dissociated from the $-\mathrm{SO}_{3} \mathrm{H}$ reacts and produces intermediators. For example, in the Fisher esterification reactions, the $\mathrm{H}^{+}$ catalyst adds to a carboxylic acid to make a reactive electrophilic intermediate, which eventually results in an $\mathrm{H}^{+}$addition elimination. The sulfonic acid catalyst demonstrates better catalytic effects compared with sulfuric acid or other heterogeneous catalysts. Second, sulfonic acid AILs have also been used as electrolytes of electrochemical devices, such as fuel cells and flow batteries, although the long-term stability of the IL solutions in the battery/fuel cell conditions has not been fully understood [27-33]. The majority of the fuel cells use the proton exchange membrane (PEM), which can separate the cathode and anode compartments and allow the transportation of $\mathrm{H}^{+}$ions thought the PEM. Nafion, a perfluorosulfonic acid membrane, is widely used in PEM fuel cells [34-38]. In recent years, IL-containing polymer membranes have been used as the PEM of fuel cells in order to improve the high temperature performance of the PEMs and fuel cells. ILs' low volatilities and high thermal stabilities allow IL-based PEM works at temperatures as high as $\sim 300{ }^{\circ} \mathrm{C}$ without observable IL evaporation and loss of electrochemical functionality. For this purpose, many cross-linked polymers with sulfonic acid functional groups have been synthesized and swollen with ILs. Extra sulfonic acids may also be added to further enhance the proton conductivity. Third, sulfonic acid-functionalized ILs are good solvents that can solubilize metal oxides and extract metals from raw materials [39,40]. Sulfonic acid AILs are milder compared with typical strong acids $\left(\mathrm{HNO}_{3}, \mathrm{H}_{2} \mathrm{SO}_{4}\right)$ for metal extraction. $\mathrm{HNO}_{3}$ and $\mathrm{H}_{2} \mathrm{SO}_{4}$ are very corrosive, and their reactions with metal oxides produce noxious and corrosive gas products. The AILs exhibit large contact area with no vapor or gas produced.

These applications, in general, are based on the strong acidic property of sulfonic acids and non-volatile liquid properties of the ILs. Therefore, the sulfonic acid dissociation, microenvironment of active protons, and the channels and mechanisms of proton transportation are very essential knowledge to know in order to understand their performance in applications and to design and develop optimistic systems for the applications. In dilute aqueous solutions, many sulfonic acids are very strong; most of the acids are ionized. However, the microenvironment, structure and interactions around the active proton in bulk ILs have not been made very clear to date. Molecular dynamics simulation indicates that the dissociation might be affected by the anions of the AILs, which can interact with the active $\mathrm{H}^{+}$[41]. Any dissociation of the acids in the AILs should be accompanied by the solvation of the $\mathrm{H}^{+}$ion by a Brønsted base, an anion in the IL systems. The $\mathrm{H}^{+}$activity will be determined by the 
relative strength of the acids and bases in the solution, based on the Brønsted-Lowry acid-base theory. In this paper, the anion in the solutions is TFSI anion which is the conjugate base of a strong acid HTFSI. The solution properties were characterized with and without the presence of extra HTFSI in the sulfonic acid/IL solutions. Conductivity and viscosity of the AIL solutions with different concentrations were measured at room temperature and elevated temperatures. The microenvironments/solvation clusters of $\mathrm{H}^{+}$in the solutions are also characterized by Raman spectroscopy. The interactions at the molecular level are further supported by computational simulation with a "mini-clusters" method. The collective properties of the interactions are reflected by the solution enthalpy $\left(\Delta H_{s o l}\right)$ that is measured by solution calorimetry.

\section{Materials and Methods}

ILs PyrrTFSI, BMITFSI, and BMIBF 4 were purchased from Ionic Liquid Technologies Inc (Heilbronn, Germany). The ILs were treated in a vacuum oven at $60^{\circ} \mathrm{C}$ overnight prior to use. All the acids, including the MSA, camphor sulfonic acid (CSA), and HTFSI, were purchased from Sigma-Aldrich, Inc (St. Louis, MO, USA). MSA and CSA were treated in vacuum oven at room temperature overnight prior to use; HTFSI was used as received.

An AC Mode Traceable ${ }^{\mathrm{TM}}$ conductivity meter (Traceable ${ }^{\circledR}$ Products Inc., Webster, TX, USA) at a constant frequency of $3 \mathrm{KHz}$ was used to measure the conductivities of pure ILs and solutions. The meter has a pair of parallel Pt plate electrodes with a cell constant of unity. The cell was calibrated by standard solutions with conductivity of 1 and $10 \mathrm{mS} / \mathrm{cm}$, respectively, prior to measurement. A hot water bath was used to control the temperature of the IL solutions. Temperature values were read by the built-in thermal couple of the conductivity probe.

A Brookfield rotational viscometer was used to measure the viscosities of pure ILs and AIL solutions at shear rates of $15-30 \mathrm{~s}^{-1}$. The viscometer was equipped with a CPA-40Z cone-shaped spindle and a built-in temperature probe. The temperature of the samples (room temperature $-70^{\circ} \mathrm{C}$ ) was controlled by circling water from a thermostat to the sample cup. The instrument was calibrated by mineral oil viscosity standards of $20 \mathrm{cP}$ and $200 \mathrm{cP}$, respectively, prior to use.

A standard "coffee-cup" calorimeter was used to measure the solution enthalpy $\left(\Delta H s_{o l}\right)$ when ILs and sulfonic acids were mixed in plastic containers that were isolated from the surroundings with aluminum foil and Styrofoam. The temperature of the system was monitored by a thermocouple connected to a computer. The specific heat capacity of the solutions was measured with a pre-heated copper slug. By measuring the dissolution of $\mathrm{CaCl}_{2}$ in $\mathrm{H}_{2} \mathrm{O}$, we estimated that there was a $28 \%$ total heat loss when the maximum temperature was reached within several minutes [42]. The measured $\Delta H s_{o l}$ values were compensated for this $28 \%$ heat loss.

A Horiba Jobin-Yvon LabRam Evolution Raman Microscope (Horiba, Edison, NJ, USA) was used to measure the Raman spectra. The excitation wavelengths were either $532 \mathrm{~nm}$ or $633 \mathrm{~nm}$. Fluorescence backgrounds were subtracted using the Labspec 6 software. Density Functional Theory (DFT) calculations of IL solvation structures were performed with the GAMESS code incorporated with the ChemBio3D program (Perkin Elmer, Waltham, MA, USA) that can compute Raman intensities. IL structures used for inputs to DFT calculations were generated using molecular mechanics and molecular dynamics simulations in the ChemBio3D software package. Initial structures, chosen with random starting geometries, were subjected to a 10 ps simulation with the MM2 force field followed by a geometry minimization using the same force field. These geometries of IL molecular cation-anion complexes with and without acid solutes were computed at the B3LYP/6-31+G* level. Raman spectra (frequencies and intensities) were computed at the same level of theory and simulated by scaling the harmonic frequencies by 0.97 and convolving the frequencies and intensities with $10 \mathrm{~cm}^{-1} \mathrm{FWHM}$ Lorentzian line shapes. 


\section{Results}

\subsection{MSA in PyrrTFSI}

MSA is a low-volatility, stable, and relatively strong acid $\left(\mathrm{pK}_{\mathrm{a}}=-1.9\right)$ that has been demonstrated to be a good catalyst for many organic reactions and a good electrolyte for electrochemical reactions [43-45]. MSA has good solubility in water and many organic solvents and has been found to be soluble or even miscible in several ILs. When MSA is added into PyrrTFSI, the conductivity of the IL solution increases from about $3 \mathrm{mS} / \mathrm{cm}$, pure PyrrTFSI, to about $6 \mathrm{mS} / \mathrm{cm}, 6 \mathrm{M}$ MSA, Figure 1A. Similar results have also been observed when MSA is dissolved in ILs BMITFSI or $\mathrm{BMIBF}_{4}$, data not shown in this paper. In our previous reports, we also found the addition of weak organic acids to ILs increased the overall conductivity of the solutions, as well as the addition of polar organic solvents [7,46,47]. On the other hand, the addition of strong acid such as HTFSI will increase the conductivity at lower concentrations and then reduce the conductivity at higher concentrations [3,4]. The strong acid $\mathrm{HBF}_{4}$ will simply increase the conductivity of the IL solutions, because of the un-removable water carried into the solution [3]. MSA is relatively strong, compared with carboxylic acids, while it is significantly weaker than HTFSI and $\mathrm{HBF}_{4}$. These results also indicate that the MSA may not ionize as much as the HTFSI in IL solutions, due to its relatively smaller $\mathrm{K}_{\mathrm{a}}$ value. Further evidence of the low ionization of MSA is that when $\mathrm{CH}_{3} \mathrm{SO}_{3}{ }^{-}$ion is added, the solution conductivity decreases, Figure 2. This result may indicate that $\mathrm{CH}_{3} \mathrm{SO}_{3}{ }^{-}$ion is not produced when MSA is dissolved in the ILs. The conductivity of the solutions increased when the solutions were heated to higher temperatures. The conductivity of the solutions was around $\sim 10 \mathrm{mS} / \mathrm{cm}$ at a temperature of $78{ }^{\circ} \mathrm{C}$. The conductivity changes as a function of the temperature (Arrhenius Plots) of MSA solution in PyrrTFSI with various concentrations was shown in Figure 1B. As the Arrhenius plots are not linear, the results were fitted with the Vogel-Fulcher-Tamman (VFT) equation of ionic conductivity $(\sigma)$ :

$$
\sigma=\sigma_{0} e^{\frac{-B}{T-T_{0}}}
$$

where $\sigma_{0}, B$, and $T_{0}$ are all constants dependent on the contents of the solution. Based on the free-volume theory $[48,49], \sigma_{0}$ may be associated with the infinite conductivity (proportional to the concentration of charge carriers) of a system at an extreme temperature, $B$ has a temperature unit and relates to the activation energy of charge carrier's motion, and $T_{0}$ is the virtual glassy transition temperature of the liquid. The values, as shown in Figure 1C, were estimated by fitting the VFT equation with the data in Figure 1B. It can be seen that the addition of MSA in the PyrrTFSI increased the $\sigma_{0}$ value (number of charge carriers) and the $B$ (apparent activation energy) slightly, while the $T_{0}$ value has no significant change. The increase of "activation energy" of the charge carriers' transportation may indicate the interactions between the ions and molecules in the solution are stronger compared with those in pure PyrrTFSI. This is also in agreement with the calorimetry results, which found dissolving MSA in PyrrTFSI to be an exothermic process. The solution enthalpy is $\sim-0.4 \pm 0.1 \mathrm{~kJ} / \mathrm{mol}$. This also indicates that the addition of the polar molecule MSA will cause the overall interactions between the charged ions and molecules to be associated more tightly through dipole interactions. The increase of the charge carriers' concentration may be attributed to the "dilution" effects of the molecular solute MSA that has break the ion clusters in the pure IL and make more mobile charge carriers in the solution. Therefore, the increase of the solution conductivity may be due to the larger number of charge carriers. In our previous report, a weaker acid, acetic acid, was dissolved in EMIOAc [7]. It was found that the increase of conductivity was due to the same effect: the increase in the number of charge carriers. On the other hand, when a non-electrolyte polar molecular solvent propylene carbonate was dissolved in ILs, the increase of solution conductivity was attributed to a different mechanism: the reduction of the activation energy ( $B$ factor in the VFT equation) [47]. The viscosity of the solutions showed opposite trends of change from solution conductivity with changing concentration and temperature, as summarized by the Walden's Rule. Increase of concentration or temperature reduces the viscosity 
of the solutions, as shown in Figures 1D and 3A. The Walden's constant (conductivity X viscosity) is relatively stable over the concentration range measured, as shown in Figure 3B.
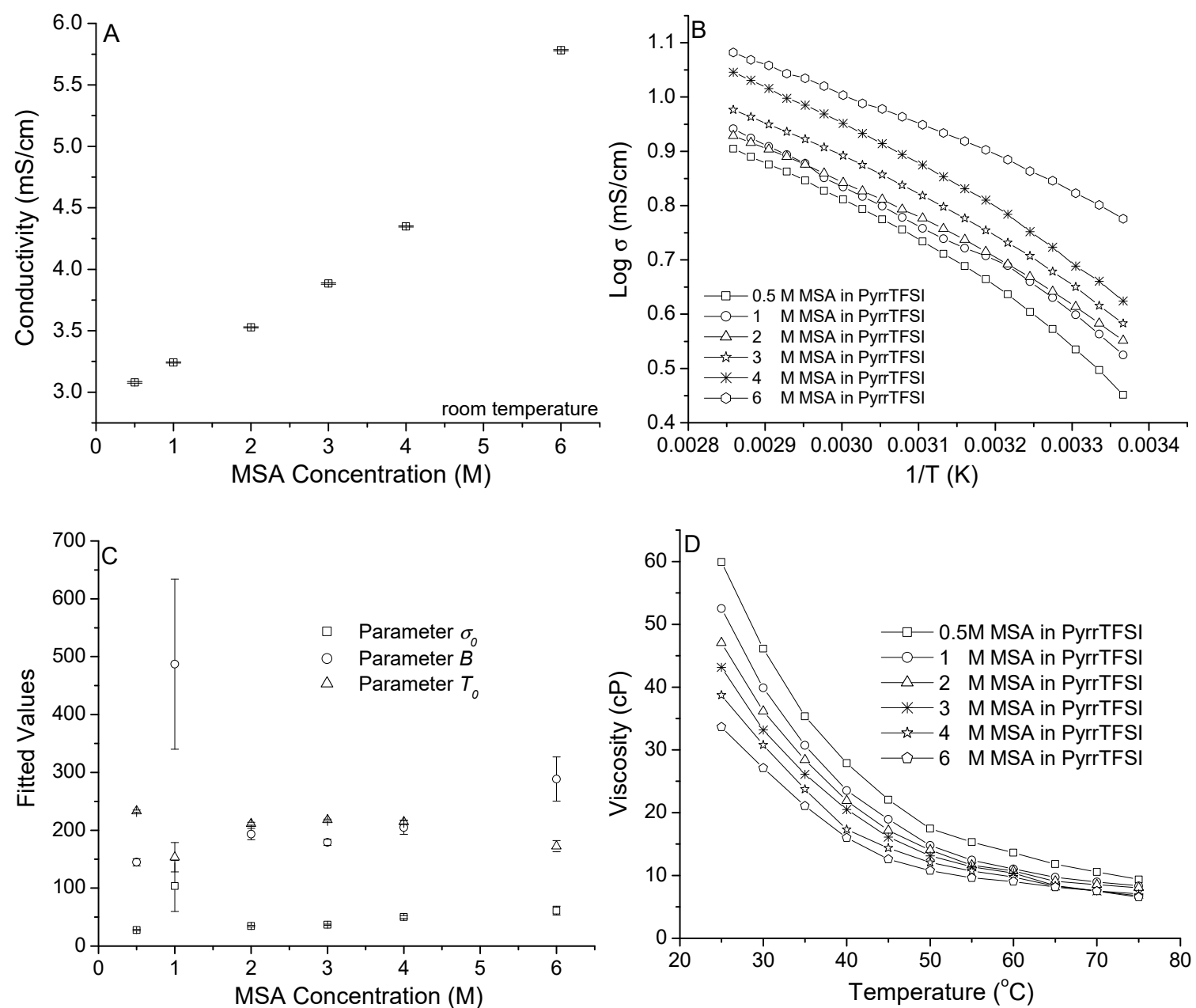

Figure 1. (A) Conductivity vs. MSA concentration in PyrrTFSI; (B) Arrhenius plots of MSA/PyrrTFSI solutions over temperature range of $23-80{ }^{\circ} \mathrm{C}$; (C) Fitted values of $\sigma_{0}, B$, and $T_{0}$ in the VFT equation; (D) Viscosity vs. temperature of the solutions with various MSA concentrations.

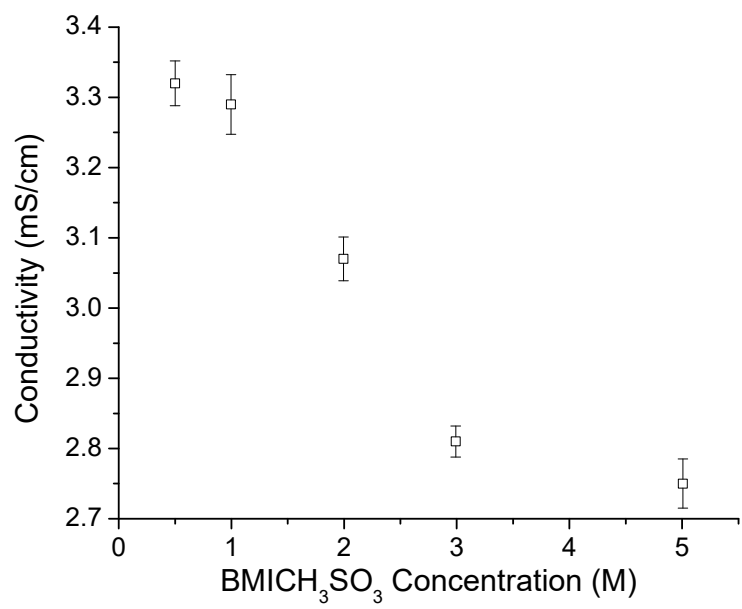

Figure 2. Conductivity of $\mathrm{BMICH}_{3} \mathrm{SO}_{3}$ solutions in $\mathrm{IL} \mathrm{BMIBF}_{4}$. 

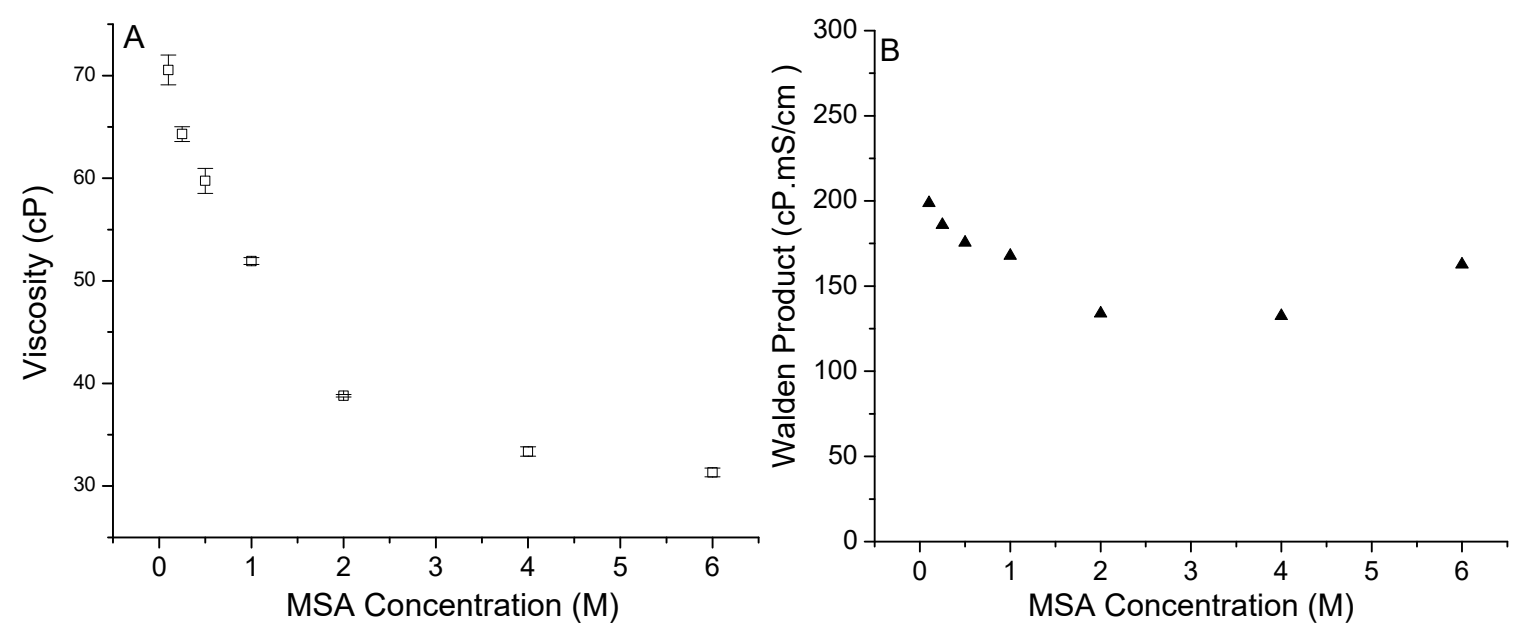

Figure 3. (A) Viscosity; and (B) Walden's Product of MSA/PyrrTFSI solutions at room temperature, $\sim 23^{\circ} \mathrm{C}$.

The Raman spectra of MSA in PyrrTFSI are shown in Figure 4. The spectrum of pure PyrrTFSI (bottom trace) clearly exhibits a peak at $740 \mathrm{~cm}^{-1}$. This was assigned to a TFSI molecular vibration that is sensitive to intermolecular interactions and IL solvation structures. In all spectra, this peak is unchanged (and all other PyrrTFSI peaks are unchanged), which indicates that the PyrrTFSI structure is unaffected by MSA. As the MSA concentration increases to $5.0 \mathrm{M}$, the appearance of a Raman band around $765 \mathrm{~cm}^{-1}$ can be identified as arising from the MSA C-S stretch mode by comparison to the Raman spectrum of pure MSA, shown as the upper trace. Other than a slight shift from $763 \mathrm{~cm}^{-1}$ (low MSA concentration) to $767 \mathrm{~cm}^{-1}$ (high MSA concentration) to $770 \mathrm{~cm}^{-1}$ (pure MSA), the MSA C-S stretch band is mostly unchanged from the pure MSA spectrum. MSA deprotonation would result in significantly larger shifts in the C-S stretch band. The Raman spectra hence indicate that the MSA structure is not affected by the PyrrTFSI, and the slight shifts in the C-S stretch frequency can be attributed to differences in solvation and solvent dielectric fields. The MSA behaves like a non-electrolyte molecule in the solution and no ionization or proton transfer can be observed.

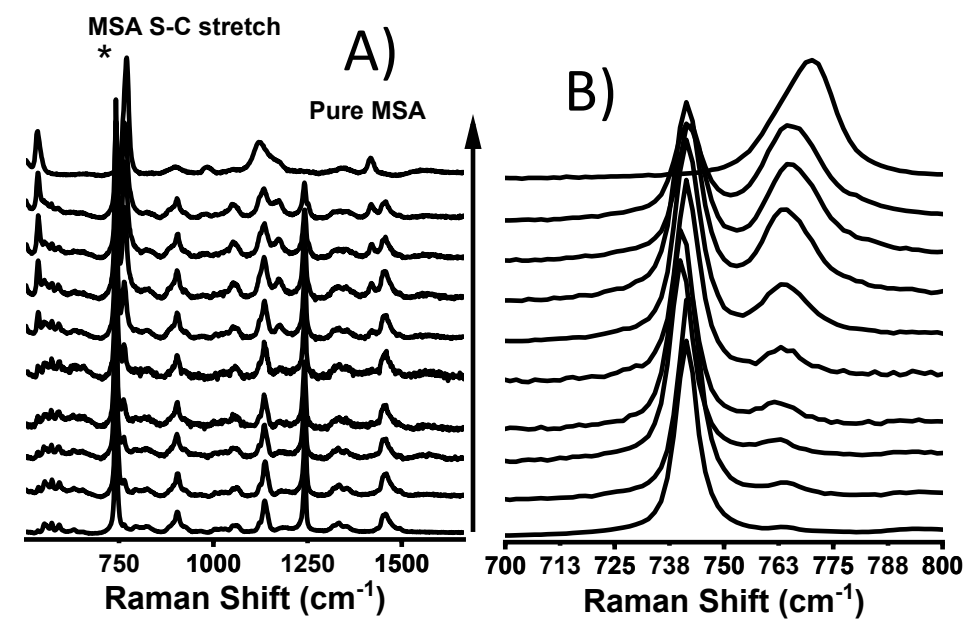

Figure 4. Raman spectra of MSA in PyrrTFSI shown with increasing MSA concentration from 0 to $5.0 \mathrm{M}$. The top trace is the Raman spectrum of pure MSA. (A) Full spectra; (B) Expanded region between 700 and $800 \mathrm{~cm}^{-1}$ to correspond to the region discussed in the text. 


\subsection{MSA in $0.4 M$ and 2.0 M HTFSI/PyrrTFSI}

HTFSI solutions in PyrrTFSI show very interesting conductivity change behaviors. The solution conductivity increases at lower concentrations and decrease at higher concentrations; a maximum conductivity value can be observed at $\sim 1$ M HTFSI [6]. The HTFSI partially ionizes in the solution and a N-H-N "bridged" structure may be formed in the solution, in which a proton is solvated by two TFSI anions. In this work, two HTFSI/PyrrTFSI solutions with different concentrations, $0.4 \mathrm{M}$ (lower than $1.0 \mathrm{M}$ ) and $2.0 \mathrm{M}$ (higher than $1.0 \mathrm{M}$ ), were used to dissolve MSA to form a series of MSA/HTFSI/PyrrTFSI solutions. Their conductivity and viscosity values are shown in Figure 5. In both solutions, the conductivity increased with the increase of MSA concentration, which is similar to the results in PyrrTFSI solutions without HTFSI. On the other hand, the viscosity increased first to a maximum value at $0.5 \mathrm{M}$ MSA and then decreased after the peaks. Meanwhile, the dissolution of MSA in the HTFSI/PyrrTFSI is also exothermic, $\Delta H=-0.20 \pm 0.15 \mathrm{~kJ} / \mathrm{mol}$ when MSA and HTFSI/PyrrTFSI are mixed at equal moles, which may also indicate slightly stronger intermolecular interactions in the solutions when MSA is added. The conductivity and viscosity data over a temperature range of $23-78{ }^{\circ} \mathrm{C}$ are plotted (Figure 6A,C), and the results are fitted with the VFT equations for conductivity and viscosity, respectively. The values of the parameters from the fitting are shown in Figure 6B,D. The VFT equation for viscosity is presented as:

$$
\eta=\eta_{0} e^{\frac{B}{T-T_{0}}}
$$

where $\eta_{0}, B$, and $T_{0}$ are constants of equation that do not depend on the concentration and temperature.

The results for both conductivity and viscosity showed relatively stable $\sigma_{0}, \eta_{0}$, and $T_{0}$ values, while the $B$ values changed more significantly with an increase in the lower concentration range and a decrease at higher concentrations. This increase and decrease in the $B$ values (proportional to the activation energy of the motion of particles in mechanical share force field for viscosity and in electrical field for conductivity, respectively) may explain the increase and decrease of the viscosity of the solutions when the concentration increases. On the other hand, in the case of conductivity, the increase of the number of charge carriers $\left(\sigma_{0}\right)$ may be more dominant in the determination of conductivity. Temperature course results in the 2.0 M HTFSI/PyrrTFSI solutions showed similar results and, therefore, are not shown in this paper.
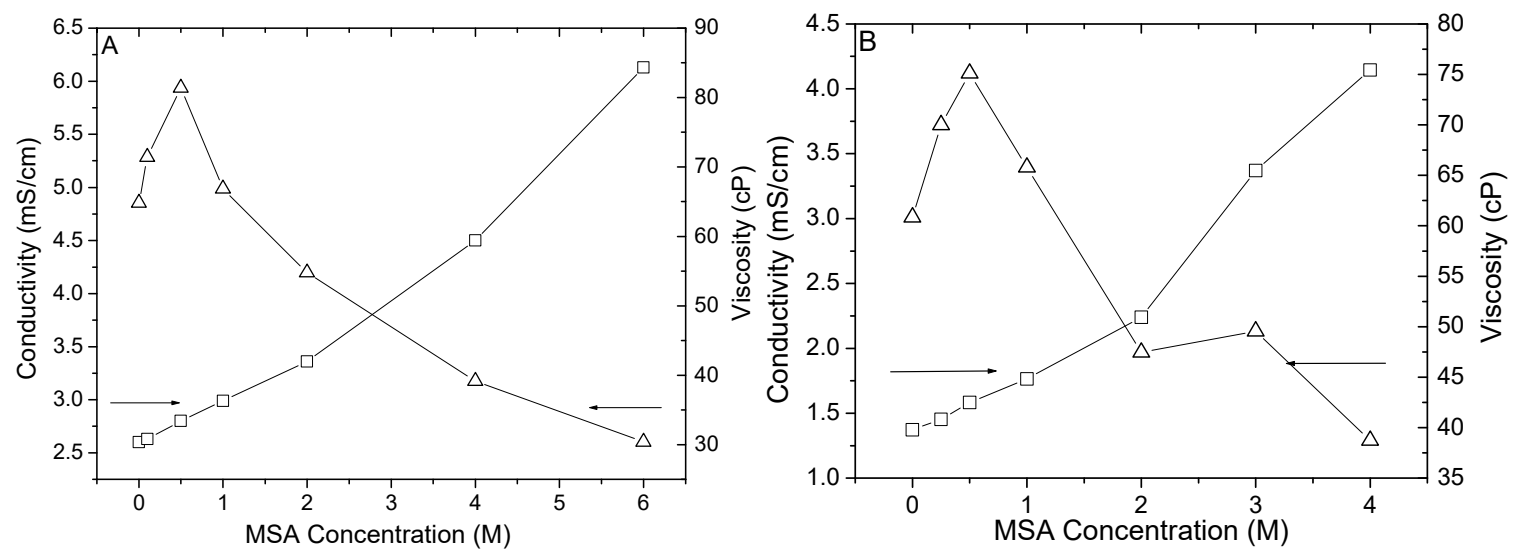

Figure 5. Conductivity $(\square)$ and viscosity $(\Delta)$ of MSA solutions in HTFSI (0.4 M)/PyrrTFSI (A), and HTFSI $(2.0 \mathrm{M}) /$ PyrrTFSI (B), at room temperature. 

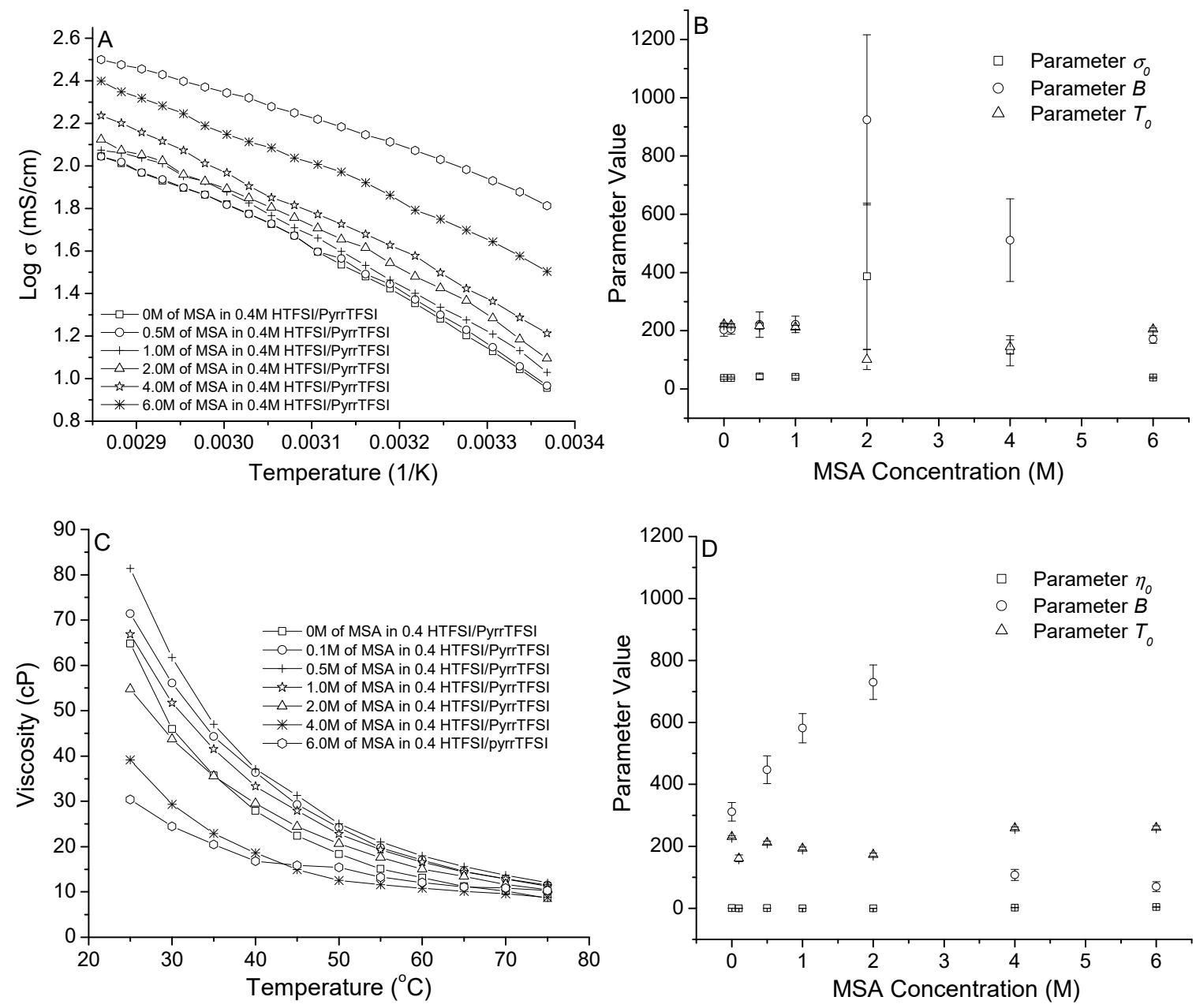

Figure 6. Conductivity (A) and viscosity (C) of MSA in HTFSI (0.4 M)/PyrrTFSI solutions at different temperatures and the value of parameters in the VFT equations fitted with the experimental data: (B) fitted from conductivity data, and (D) fitted from viscosity data.

The Raman spectra of MSA in the HTFSI/PyrrTFSI solutions are shown in Figure 7. The relevant spectral region is between 700 and $800 \mathrm{~cm}^{-1}$, so only this region is shown. A doublet Raman signal observed for the TFSI molecular vibrational mode was used to identify the HTFSI-PyrrTFSI bridged-proton structure [6]. In Figure 7, the TFSI molecular vibration exhibits a single Raman band at $740 \mathrm{~cm}^{-1}$, indicating that the bridged-proton structure is not formed with $0.4 \mathrm{M}$ HTFSI. The MSA C-S stretch mode appears with increasing MSA concentration as a Raman band at $\sim 765 \mathrm{~cm}^{-1}$. This position is nearly identical to the band position in the MSA/PyrrTFSI solutions (Figure 7A) and suggests that the MSA does not interact with the HTFSI or PyrrTFSI molecules, and does not form a bridged-proton structure. With 2.0 M HTFSI in PyrrTFSI (Figure 7B), the doublet TFSI molecular vibration band is observed, confirming the presence of the HTFSI-PyrrTFSI N-H-N "bridged" structure. With increasing MSA concentration, this doublet is unchanged and the MSA C-S stretch band appears mostly unchanged relative to the pure MSA spectrum (top trace). This suggests that the MSA does not alter the structure or stability of the HTFSI-PyrrTFSI interactions.

The DFT-computed structures of MSA in the HTFSI/PyrrTFSI solutions are shown in Figure 8. Figure 8A shows the HTFSI-TFSI N-H-N "bridged" structure surrounded by pyrrolidinium cations and a non-interacting MSA molecule while 8B shows MSA interacting with and disrupting the HTFSI-TFSI interaction. These calculated clusters are most relevant to the high-concentration samples which have high-concentration MSA and HTFSI relative to the PyrrTFSI. The simulated Raman and IR spectra are compared to the experimental spectra in Figure 9. The relative $\Delta G$ values from the DFT 
calculations are provided in $\mathrm{kJ} / \mathrm{mol}$. The N-H-N "bridged" structure is that shown in Figure $9 \mathrm{~A}$ and the $\mathrm{N}-\mathrm{H}-\mathrm{O}$ "bridged" structure is that shown in Figure 9B. The N-H-N structure is more favorable at about $20.6 \mathrm{~kJ} / \mathrm{mol}$, which is a large enough number to suggest that the N-H-O "bridged" structure would not be observed experimentally. This is consistent with the spectroscopic experiment-theory comparison. Previously, we have shown that the vibrational frequencies around $750 \mathrm{~cm}^{-1}$ are underestimated in our DFT calculations [6], and in that context, the N-H-N simulated spectra are closer to the experiments. Figure 9, therefore, provides strong evidence that the N-H-N "bridged" structure is most consistent with the 5.0 M MSA and 2.0 M HTFSI in PyrrTFSI. Together with Figures 8 and 9, we can conclude that the MSA does not interact with the HTFSI-TFSI structure and is present in solution as a non-interacting molecular solute.

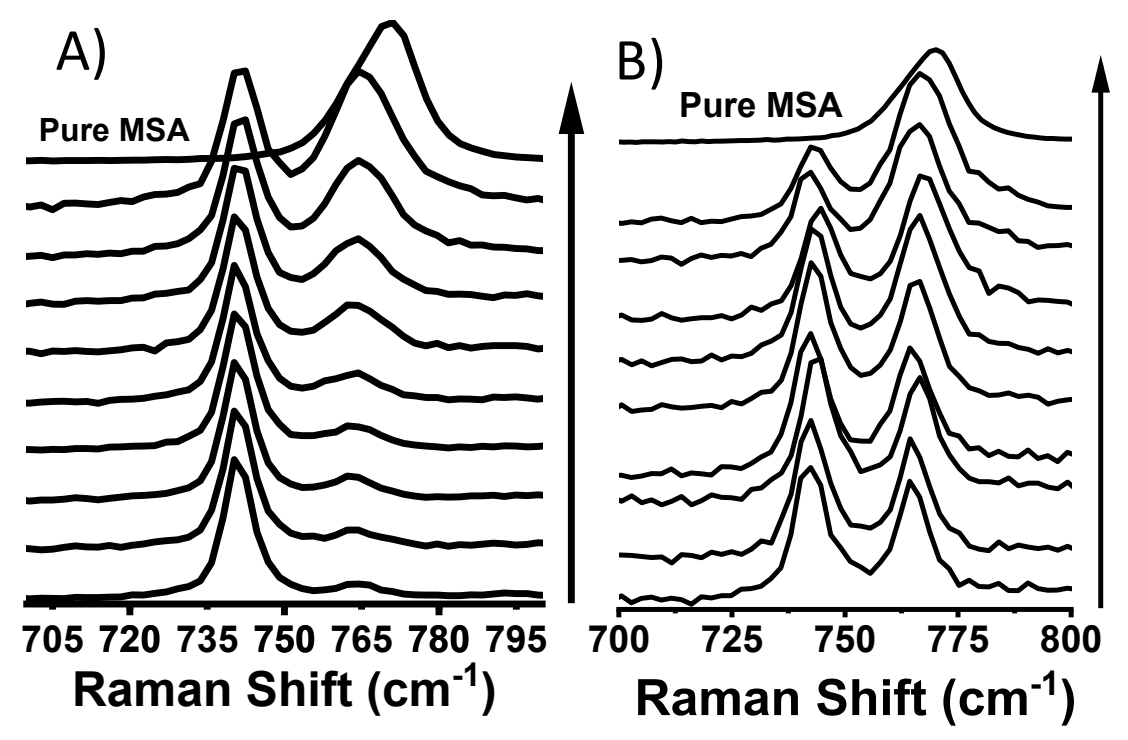

Figure 7. Raman spectra of MSA/HTFSI/PyrrTFSI solutions shown as a function of increasing MSA concentration in constant HTFSI concentrations. (A) In 0.4 M HTFSI/PyrrFTSI solutions; (B) in $2.0 \mathrm{M}$ HTFSI/PyrrFTSI solutions.
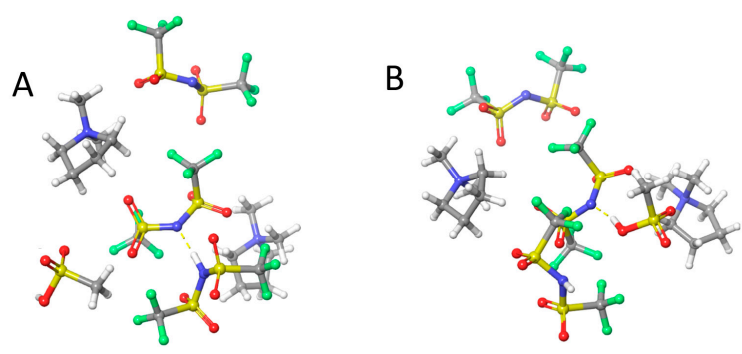

Figure 8. B3LYP/6-31+G* ${ }^{*}$ structures of MSA/HTFSI/PyrrTFSI AILs. For computational simplicity, the cation is 1,3-dimethylimidazolium. (A) N-H-N "bridged" structure, in which the HTFSI is hydrogen-bonded to a TFSI anion while the MSA is not involved in hydrogen bonding; (B) N-H-O "bridged" structure, in which the MSA is hydrogen bonded to a TFSI anion. 

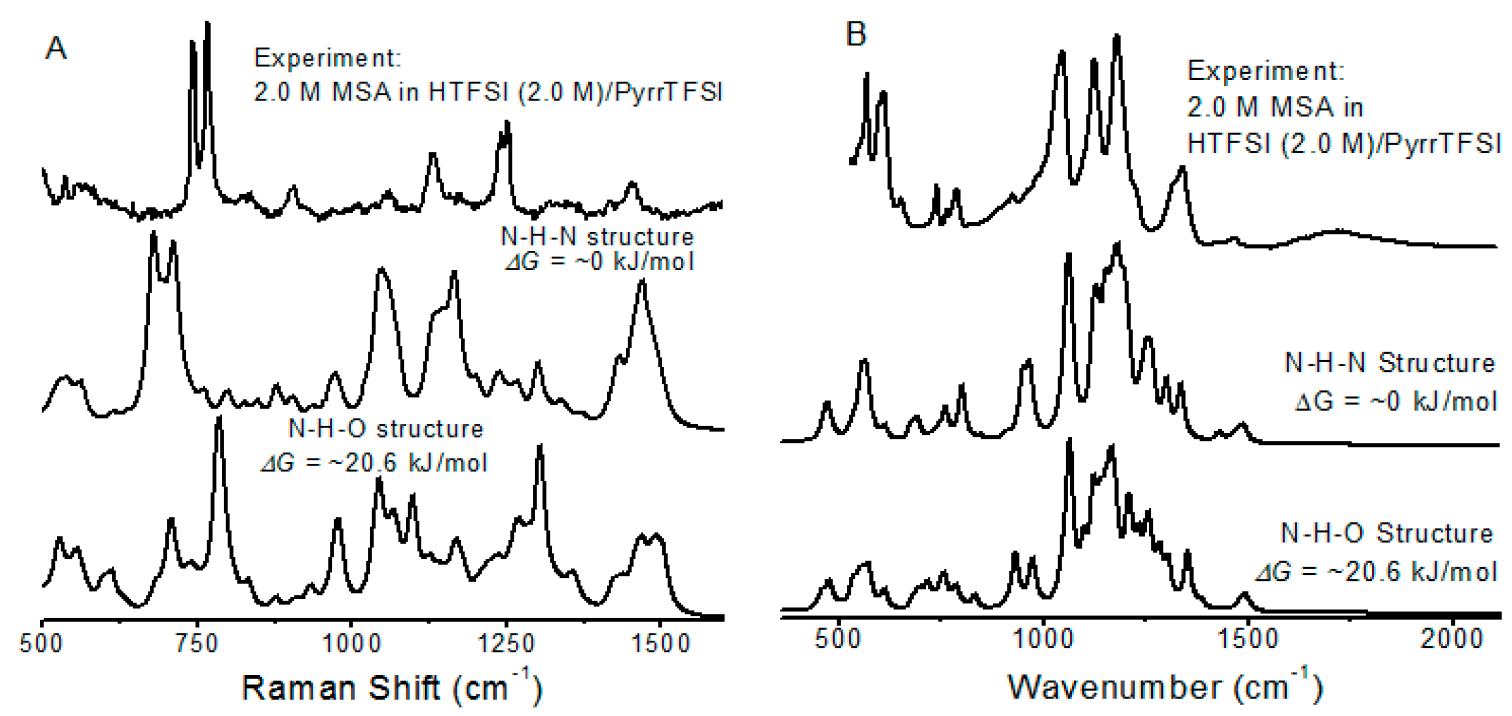

Figure 9. The experimental Raman spectrum (A) and IR spectrum (B) are compared to simulated Raman spectra (A) and simulated IR spectra (B) for the N-H-N "bridged" structure from Figure 8A and the N-H-O "bridged" structure from Figure 8B. In both panels A and B, the top trace is the experimental result and the bottom two traces are simulations.

\subsection{CSA in ILs and HTFSI/IL}

CAS is another organic sulfonic acid with $\mathrm{pK}_{\mathrm{a}}$ of 1.2 and limited solubility in ILs. It is weaker than MSA, but still stronger than most of the carboxylic acids. When CSA is dissolved in $\mathrm{BMIBF}_{4}$, the conductivity of the solution decreases, as shown in Figure 10A; the "dilution" effect that will increase the conductivity is not observed. In the same IL, the addition of HTFSI up to $0.8 \mathrm{M}$ demonstrated no significant effects on the solution conductivity, Figure 10B, probably because of the balance of two effects of HTFSI, which are increasing the ion migration activation energy and the number of charge carriers that will cause the conductivity change to the opposite directions. When both CSA and HTFSI present in the $\mathrm{BMIBF}_{4}$ solutions, a synergistic effect that increases the solution conductivity is observed, Figure 11. At low HTFSI concentrations $(<0.4 \mathrm{M})$, the conductivity of the solution also decreased when CSA was added to the solution. However, the conductivity increased when CSA was added to $\mathrm{BMIBF}_{4}$ containing $0.4 \mathrm{M}$ or $0.8 \mathrm{M}$ HTFSI. The maximum conductivity was obtained at a CSA concentration of $0.05 \mathrm{M}$ in $0.4 \mathrm{M}$ HTFSI/BMIBF4 and at CSA concentration of $0.1 \mathrm{M}$ in $0.8 \mathrm{M}$ HTFSI/BMIBF 4.
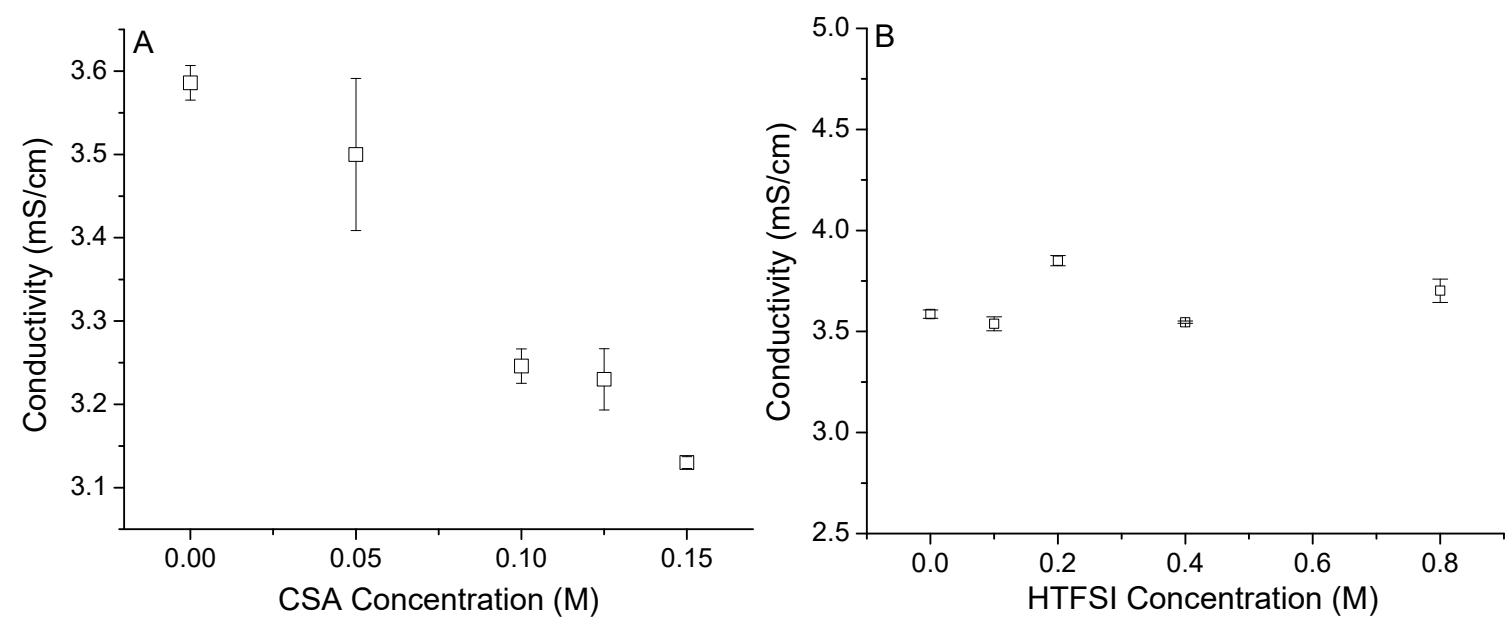

Figure 10. Conductivity of CSA solutions in $\mathrm{BMIBF}_{4}(\mathbf{A})$ and $\mathrm{HTFSI}$ solutions in $\mathrm{BMIBF}_{4}(\mathbf{B})$. 


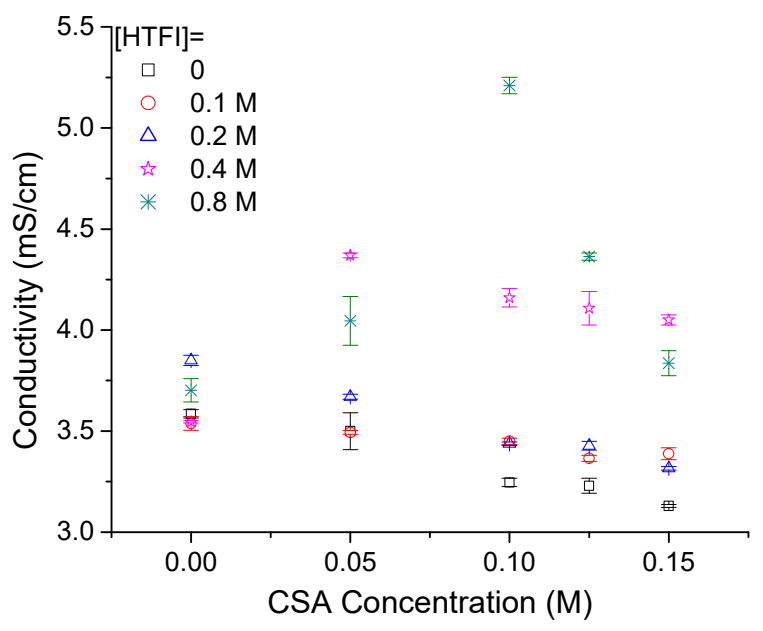

Figure 11. Conductivity of CSA solutions in $\mathrm{HTFSI}_{\mathrm{BMIBF}}$.

\section{Conclusions}

MSA and CSA are both relatively strong organic acids. MSA is very soluble in ILs and CSA has a solubility of about $0.15 \mathrm{M}$. When MSA is dissolved in ILs, it increases the solution conductivity and decreased the solution viscosity, while the CSA has the opposite effects. It has been found that the MSA can dilute the IL and release more "free" ions or ion clusters, while it can also increase the "activity energy" of the migration, which means stronger intermolecular interactions. This is also reflected by the exothermic effect of dissolution. After the addition of the MSA, the Raman spectra of the solutions indicate that there is not observable ionization or proton transfer in the IL solutions with or without the existence of strong acid HTFSI in the solution. At high concentrations, HTFSI can form dimers through N-H-N "bridge" hydrogen bonds between the TFSI and the proton. The MSA added into the solution is non-interactive and cannot affect the N-H-N "bridged" TFSI dimers. On the other hand, the CSA decreased the solution conductivity that may indicate a stronger solvation by the ions. In one of our previous reports, we found that the active hydrogen of MSA can react with acetate ion in ILs and produce acetic acid, which is a proton transfer reaction between a Brønsted acid and a base. However, in $\mathrm{TFSI}^{-}$or $\mathrm{BF}_{4}^{-}$ILs, the anions are too weak as proton acceptors, and therefore, the ionization of MSA is not observed in these systems. Overall, in the $\mathrm{TFSI}^{-}$or $\mathrm{BF}_{4}{ }^{-} \mathrm{ILs}$, the sulfonic acids do not ionize significantly nor affect the solvation structures of the strong acid HTFSI.

Author Contributions: Experimental measurements, A.T.T., J.T., P.H.L., A.D.M., D.J.W., and O.C.; computational simulation, B.L.S.; writing, L.Y., T.D.V.; supervision, L.Y., T.D.V.; project administration, L.Y., T.D.V.; funding acquisition, L.Y., T.D.V.

Funding: This research was funded by NSF of the US, grant number CHE-1362493 and O.C. was funded by the American Chemical Society Project SEED program administrated by the South Jersey Local Section.

Conflicts of Interest: The authors declare no conflict of interest.

\section{References}

1. Rogers, R.D.; Seddon, K.R. Ionic Liquids: Industrial Applications for Green Chemistry; Oxford University Press: Washington, DC, USA, 2002.

2. Amarasekara, A.S. Acidic Ionic Liquids. Chem. Rev. 2016, 116, 6133-6183. [CrossRef] [PubMed]

3. Yu, L.; Clifford, J.; Pham, T.T.; Almaraz, E.; Perry, F., III; Caputo, G.A.; Vaden, T.D. Conductivity, Spectroscopic, and Computational Investigation of $\mathrm{H}_{3} \mathrm{O}^{+}$Solvation in Ionic Liquid BMIBF4. J. Phys. Chem. B 2013, 117, 7057-7064. [CrossRef] [PubMed]

4. Yu, L.; Pizio, B.S.; Vaden, T.D. Conductivity and Spectroscopic Investigation of Bis(trifluoromethanesulfonyl)imide Solution in Ionic Liquid 1-Butyl-3-methylimidazolium Bis(trifluoromethanesulfonyl)imide. J. Phys. Chem. B 2012, 116, 6553-6560. [CrossRef] [PubMed] 
5. Margaretta, E.; Olmeda, C.; Yu, L. Doped Polyaniline in Bronsted Acid Ionic Liquid 1-Butyl-3methylimidazolium bis trifluoromethyl(sulfonyl) imide/Bis trifluoromethyl(sulfonyl) imide. J. Appl. Polym. Sci. 2013, 127, 2453-2457. [CrossRef]

6. Munson, K.T.; Vergara, J.; Yu, L.; Vaden, T.D. Characterization of the Bridged Proton Structure in HTFSI Acid Ionic Liquid Solutions. J. Phys. Chem. B 2015, 119, 6304-6310. [CrossRef]

7. Renda, C.M.; Patel, Y.K.; Henshaw, L.R.; Munson, K.T.; Fiebig, O.C.; Tran, A.T.; Shriver, J.; Cruz, J.; Yu, L.; Vaden, T.D. Thermodynamic and conductivity properties of acetic acid EMIMOAc ionic liquid solutions. J. Mol. Liq. 2016, 216, 710-715. [CrossRef]

8. Smith, M.B. Organic Chemistry: An Acid-Base Approach, 2nd ed.; CRC Press: Boca Raton, FL, USA, 2016.

9. Guthrie, J.P. Hydrolysis of esters of oxy acids: pKa values for strong acids; Brønsted relationship for attack of water at methyl; free energies of hydrolysis of esters of oxy acids; and a linear relationship between free energy of hydrolysis and pKa holding over a range of $20 \mathrm{pK}$ units. Can. J. Chem. 1978, 56, 2342-2354. [CrossRef]

10. Ma, X.-X.; Zhang, Q.-B.; Wei, J.; Pan, Y.; Guan, W.; Yang, J.-Z. Study on enthalpy and molar heat capacity of solution for ionic liquid C(3)mim OAc (1-propyl-3-methylimidazolium acetate). J. Chem. Thermodyn. 2013, 65, 91-94. [CrossRef]

11. Forbes, D.C.; Weaver, K.J. Brønsted acidic ionic liquids: The dependence on water of the Fischer esterification of acetic acid and ethanol. J. Mol. Catal. A Chem. 2004, 214, 129-132. [CrossRef]

12. Liu, X.; Ma, H.; Wu, Y.; Wang, C.; Yang, M.; Yan, P.; Welz-Biermann, U. Esterification of glycerol with acetic acid using double SO3H-functionalized ionic liquids as recoverable catalysts. Green Chem. 2011, 13, 697-701. [CrossRef]

13. Huang, B.H.; Li, Z.J.; Wang, Y.F.; Zhang, K.; Fang, Y.X. Esterification catalyzed by Bronsted acidic ionic liquids. Acta Chim. Sin. 2008, 66, 1837-1844.

14. Castanheiro, J.E.; Ramos, A.M.; Fonseca, I.M.; Vital, J. Esterification of acetic acid by isoamylic alcohol over catalytic membranes of poly(vinyl alcohol) containing sulfonic acid groups. Appl. Catal. A Gen. 2006, 311, 17-23. [CrossRef]

15. Liu, S.; Xie, C.; Yu, S.; Liu, F.; Ji, K. Esterification of alpha-pinene and acetic acid using acidic ionic liquids as catalysts. Catal. Commun. 2008, 9, 1634-1638. [CrossRef]

16. Cui, X.; Cai, J.; Zhang, Y.; Li, R.; Feng, T. Kinetics of Transesterification of Methyl Acetate and n-Butanol Catalyzed by Ionic Liquid. Ind. Eng. Chem. Res. 2011, 50, 11521-11527. [CrossRef]

17. Tao, D.-J.; Zhang, X.-L.; Hu, N.; Li, Z.-M.; Chen, X.-S. Kinetics Study of the Esterification of Acetic Acid with Methanol using Low-Corrosive Bronsted Acidic Ionic Liquids as Catalysts. Int. J. Chem. React. Eng. 2012. [CrossRef]

18. Fraga-Dubreuil, J.; Bourahla, K.; Rahmouni, M.; Bazureau, J.P.; Hamelin, J. Catalysed esterifications in room temperature ionic liquids with acidic counteranion as recyclable reaction media. Catal. Commun. 2002, 3, 185-190. [CrossRef]

19. Cole, A.C.; Jensen, J.L.; Ntai, I.; Tran, K.L.T.; Weaver, K.J.; Forbes, D.C.; Davis, J.H. Novel Brønsted Acidic Ionic Liquids and Their Use as Dual Solvent-Catalysts. J. Am. Chem. Soc. 2002, 124, 5962-5963. [CrossRef]

20. Irimescu, R.; Kato, K. Lipase-catalyzed enantioselective reaction of amines with carboxylic acids under reduced pressure in non-solvent system and in ionic liquids. Tetrahedron Lett. 2004, 45, 523-525. [CrossRef]

21. Greaves, T.L.; Drummond, C.J. Protic Ionic Liquids: Properties and Applications. Chem. Rev. 2007, 108, 206-237. [CrossRef]

22. Joseph, T.; Sahoo, S.; Halligudi, S.B. Bronsted acidic ionic liquids: A green, efficient and reusable catalyst system and reaction medium for Fischer esterification. J. Mol. Catal. A Chem. 2005, 234, 107-110. [CrossRef]

23. Vafaeezadeh, M.; Alinezhad, H. Bronsted acidic ionic liquids: Green catalysts for essential organic reactions. J. Mol. Liq. 2016, 218, 95-105. [CrossRef]

24. Liu, Y.; Wang, Y.T.; Liu, T.; Tao, D.J. Facile synthesis of fructone from ethyl acetoacetate and ethylene glycol catalyzed by SO3H-functionalized Bronsted acidic ionic liquids. RSC Adv. 2014, 4, 22520-22525. [CrossRef]

25. Ghorbani, M.; Noura, S.; Oftadeh, M.; Gholami, E.; Zolfigol, M.A. Novel ionic liquid 2-Eim HSO4 as a dual catalytic-solvent system for preparation of hexahydroquinolines under green conditions. RSC Adv. 2015, 5, 55303-55312. [CrossRef] 
26. Peng, Q.H.; Mahmood, K.; Wu, Y.; Wang, L.L.; Liang, Y.Y.; Shen, J.N.; Liu, Z.P. A facile route to realize the copolymerization of L-lactic acid and epsilon-caprolactone: Sulfonic acid-functionalized Bronsted acidic ionic liquids as both solvents and catalysts. Green Chem. 2014, 16, 2234-2241. [CrossRef]

27. Noda, A.; Susan, M.A.B.H.; Kudo, K.; Mitsushima, S.; Hayamizu, K.; Watanabe, M. Brønsted Acid-Base Ionic Liquids as Proton-Conducting Nonaqueous Electrolytes. J. Phys. Chem. B 2003, 107, 4024-4033. [CrossRef]

28. Nakamoto, H.; Watanabe, M. Bronsted acid-base ionic liquids for fuel cell electrolytes. Chem. Commun. 2007. [CrossRef]

29. Lee, S.Y.; Yasuda, T.; Watanabe, M. Fabrication of protic ionic liquid/sulfonated polyimide composite membranes for non-humidified fuel cells. J. Power Sources 2010, 195, 5909-5914. [CrossRef]

30. Diao, H.B.; Yan, F.; Qiu, L.H.; Lu, J.M.; Lu, X.H.; Lin, B.C.; Li, Q.; Shang, S.M.; Liu, W.M.; Liu, J.G. High Performance Cross-Linked Poly(2-acrylamido-2-methylpropanesulfonic acid)-Based Proton Exchange Membranes for Fuel Cells. Macromolecules 2010, 43, 6398-6405. [CrossRef]

31. Schmidt, C.; Gluck, T.; Schmidt-Naake, G. Modification of Nafion membranes by impregnation with ionic liquids. Chem. Eng. Technol. 2008, 31, 13-22. [CrossRef]

32. Fuller, J.; Breda, A.C.; Carlin, R.T. Ionic Liquid-Polymer Gel Electrolytes. J. Electrochem. Soc. 1997, 144, L67-L70. [CrossRef]

33. Robertson, N.J.; Kostalik, H.A.; Clark, T.J.; Mutolo, P.F.; AbruñA, H.C.D.; Coates, G.W. Tunable High Performance Cross-Linked Alkaline Anion Exchange Membranes for Fuel Cell Applications. J. Am. Chem. Soc. 2010, 132, 3400-3404. [CrossRef] [PubMed]

34. Mcintosh, S.; Gorte, R.J. Direct Hydrocarbon Solid Oxide Fuel Cells. Chem. Rev. 2004, 104, 4845-4866. [CrossRef] [PubMed]

35. Whittingham, M.S.; Zawodzinski, T. Introduction: Batteries and Fuel Cells. Chem. Rev. 2004, 104, $4243-4244$. [CrossRef] [PubMed]

36. Winter, M.; Brodd, R.J. What Are Batteries, Fuel Cells, and Supercapacitors? Chem. Rev. 2004, 104, $4245-4270$. [CrossRef] [PubMed]

37. Mehta, V.; Cooper, J.S. Review and analysis of PEM fuel cell design and manufacturing. J. Power Sources 2003, 114, 32-53. [CrossRef]

38. Aricò, A.S.; Srinivasan, S.; Antonucci, V. DMFCs: From Fundamental Aspects to Technology Development. Fuel Cells 2001, 1, 133-161. [CrossRef]

39. Dupont, D.; Raiguel, S.; Binnemans, K. Sulfonic acid functionalized ionic liquids for dissolution of metal oxides and solvent extraction of metal ions. Chem. Commun. 2015, 51, 9006-9009. [CrossRef]

40. Dupont, D.; Renders, E.; Binnemans, K. Alkylsulfuric acid ionic liquids: A promising class of strongly acidic room-temperature ionic liquids. Chem. Commun. 2016, 52, 4640-4643. [CrossRef]

41. Shan, W.D.; Yang, Q.W.; Su, B.G.; Bao, Z.B.; Ren, Q.L.; Xing, H.B. Proton Microenvironment and Interfacial Structure of Sulfonic-Acid-Functionalized Ionic Liquids. J. Phys. Chem. C 2015, 119, 20379-20388. [CrossRef]

42. Andriola, A.; Singh, K.; Lewis, J.; Yu, L. Conductivity, Viscosity, and Dissolution Enthalpy of LiNTF2 in Ionic Liquid BMINTF2. J. Phys. Chem. B 2010, 114, 11709-11714. [CrossRef]

43. Tian, Y.; Meng, X.; Duan, J.-Y.; Shi, L. A Novel Application of Methanesulfonic Acid as Catalyst for the Alkylation of Olefins with Aromatics. Ind. Eng. Chem. Res. 2012, 51, 13627-13631. [CrossRef]

44. Gazeau-Bureau, S.; Delcroix, D.; Martín-Vaca, B.; Bourissou, D.; Navarro, C.; Magnet, S. Organo-Catalyzed ROP of $\varepsilon$-Caprolactone: Methanesulfonic Acid Competes with Trifluoromethanesulfonic Acid. Macromolecules 2008, 41, 3782-3784. [CrossRef]

45. Gernon, D.M.; Wu, M.; Buszta, T.; Janney, P. Environmental benefits of methanesulfonic acid. Comparative properties and advantages. Green Chem. 1999, 1, 127-140. [CrossRef]

46. Tran, A.T.; Lam, P.H.; Miller, A.; Walczyk, D.J.; Tomlin, J.; Vaden, T.D.; Yu, L. Proton transfer and esterification reactions in EMIMOAc-based acidic ionic liquids. RSC Adv. 2017, 7, 18333-18339. [CrossRef]

47. Lam, P.H.; Tran, A.T.; Walczyk, D.J.; Miller, A.M.; Yu, L. Conductivity, viscosity, and thermodynamic properties of propylene carbonate solutions in ionic liquids. J. Mol. Liq. 2017, 246, 215-220. [CrossRef] 
48. Kuan, W.-F.; Remy, R.; Mackay, M.E.; Epps, T.H., III. Controlled ionic conductivity via tapered block polymer electrolytes. RSC Adv. 2015, 5, 12597-12604. [CrossRef]

49. Umecky, T.; Saito, Y.; Okumura, Y.; Maeda, S.; Sakai, T. Ionization Condition of Lithium Ionic Liquid Electrolytes under the Solvation Effect of Liquid and Solid Solvents. J. Phys. Chem. B 2008, 112, 3357-3364. [CrossRef] [PubMed]

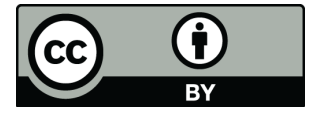

(C) 2019 by the authors. Licensee MDPI, Basel, Switzerland. This article is an open access article distributed under the terms and conditions of the Creative Commons Attribution (CC BY) license (http://creativecommons.org/licenses/by/4.0/). 